\title{
Role of physical water properties and environmental disturbances on the diversity of coastal macrophyte and invertebrate communities in a brackish water ecosystem
}

\author{
J. Kotta, H. Orav-Kotta \& M. Pärnoja \\ Estonian Marine Institute, University of Tartu, Estonia
}

\begin{abstract}
Biodiversity is important in maintaining ecosystem viability and the knowledge on how biodiversity is regulated and maintained is a prerequisite for the sustainable management of natural resources. Using three different diversity indices (macrozoobenthos community index, number of functional traits, community heterogeneity), we evaluated the role of physical water properties (water temperature, salinity, and velocity), coastal topography (depth and coastal slope), ice scouring (ice cover and duration) and eutrophication (water transparency, phytoplankton biomass) on benthic macrophyte and invertebrate communities in a brackish water ecosystem of the Baltic Sea. The analyses were performed at multiple spatial scales in order to identify scale-dependent relationships between the environment and biota as well as to promote our understanding of the patterns of macroalgal and invertebrate diversity in the coastal seascapes. The studied indices responded well to the changes in ambient environment and the links between environmental variables and indices were always the strongest at $5 \mathrm{~km}$ spatial scale. In general ice conditions, coastal topography and eutrophication had the strongest and physical water properties had the weakest effect to the studied indices. The eutrophication induced effects were the strongest at seascape scales and these are the scales at which the impacts of eutrophication on coastal biota should be assessed.
\end{abstract}

Keywords: biodiversity, bioindication, eutrophication, climate change. 


\section{Introduction}

The cumulative effects of multiple human stressors such as resource extraction, pollution, habitat destruction, spread of non-indigenous species, and climate change have ever-increasing negative impacts on ecosystem integrity. Elevated biodiversity, however, are believed to play an important role in safeguarding ecosystem integrity and services under perturbed conditions over long periods of time [1, 2]. These ecological effects of biodiversity make the increased biodiversity a valuable asset to humans. Thus, it becomes important to monitor biodiversity and define the contribution of local hydrophysical, geomorphology and weather conditions as well as human induced eutrophication to the variability of biodiversity.

The Baltic Sea is a seasonally varying system with prominent gradients in abiotic variables [3]. Salinity is considered to be the most important regional factor setting the distribution limits of algal species. Low salinity values result in low species and functional diversity but also in a peculiar mixture of marine, limnic and brackish water species in the Baltic Sea area [4, 5]. The area is characterized by strong fluctuation in temperature and light. Severe storms and ice scour are the prevailing physical disturbances [6-8]. It is generally accepted that abiotic environmental factors rather than biotic interactions control the benthic algal and invertebrate communities in the Baltic Sea [4, 9, 10]. Among anthropogenic pressures the large-scale nutrient enrichment is known to increase pelagic productivity, turbidity, sedimentation of organic matter and frequency of hypoxia and thereby limit benthic primary production, recruitment as well as control the long-term changes of benthic communities in the Baltic Sea area (e.g. [11-13]).

Knowledge on the relative importance of all these interacting processes on benthic communities is only just starting to emerge [14-18]. These studies confirm that the degree of interaction between different pressures is not consistent but varies across sites or species [19]. In order to conserve and sustainably use biological diversity, however, local the pressure-diversity relationships need to be established.

Different aspects of biodiversity can be measured using various ecological indicators. In the current study we focused on three different aspects of biodiversity - local species diversity, functional richness and synchronicity of seascape diversity. Owing to large natural variability of the Baltic Sea environment and the opportunistic character of many benthic species, we expect that the variability of indices, which included only the element of diversity, is a function of local geomorphology and hydrophysical characteristics of the environment. We also expect that such indices are largely unresponsive to local human-induced pressures such as coastal eutrophication. In addition some analyses also included sensitivities of species to environmental pressures and we expect that these indicators primarily reflect the intensity of eutrophication and less those variables related to physical water properties. 


\section{Material and methods}

\subsection{Study area}

This study was carried out in the northeastern Gulf of Riga, the Baltic Sea. The Gulf of Riga is a wide, shallow, semi-enclosed brackish-water ecosystem of the Baltic Sea. A huge drainage area $\left(134000 \mathrm{~km}^{2}\right)$ supplies the gulf with fresh water, which mostly enters the southern part of the basin. The average salinity varies from $0.5-2.0$ in surface layers in its southern and northeastern areas to 7 in the straits. In most parts, however, the salinity is 5.0-6.5 and there is no permanent halocline. Due to the shallowness of the gulf, the dynamics of both its surface and deep water temperatures is directly coupled with air temperatures. The gulf is more eutrophicated as the Baltic Proper. In general, the bottom relief of the area is quite flat, with gentle slopes towards deeps. The northern part of the gulf is characterized by a wide coastal zone with diverse bottom topography and extensive reaches of boulders. The southern part of the Gulf of Riga is more exposed; steep and soft substrate prevails ([20] and references therein).

\subsection{Sample collection}

The benthic community sampling and sample analysis followed the guidelines developed for the HELCOM COMBINE program [21]. An Ekman-type bottom grab sampler $\left(0.02 \mathrm{~m}^{2}\right)$ was used on soft sediment and a diver-operated metal frame $\left(0.04 \mathrm{~m}^{2}\right)$ was used to collect samples on hard substrate. A total of 195 stations were sampled and three replicate frame samples were taken in each station once a year in summers 2011 and 2012. During sampling the geographic coordinates, depth, and sediment types were recorded. Samples were sieved through a $0.25 \mathrm{~mm}$ mesh and the residuals were placed in plastic bags. Samples were preserved in a deep freezer at $-20^{\circ} \mathrm{C}$. In the laboratory, all invertebrate and macrophyte species were identified in the samples. Dry weights of all taxa were obtained after keeping the material 2 weeks at $60^{\circ} \mathrm{C}$.

\subsection{Indices}

\subsubsection{Macrozoobenthos community index (ZKI)}

The structure of benthic assemblages responds diversely to many kinds of stresses because these assemblages typically include organisms with a wide range of physiological tolerances, feeding modes, and trophic interactions. In order to make this information usable for water quality assessment, the ZKI index divides the macrofauna into three distinguished groups according to their sensitivity to an increasing stress (including eutrophication). Species belonging to class 1 are those that can be found at heavily eutrophicated conditions, species belonging to class 2 are those that gain biomass under moderate eutrophication conditions, and class 3 species are those typical to pristine conditions. The index also takes into account species number at station and compensates this diversity term for salinity gradients. The compensation term is based on waterbodyspecific maximum values for species number calculated from the entire content 
of national database. The index is currently used when assessing the water quality in Estonia in the frame of the EU Water Framework Directive [22].

The equation of the ZKI index is as follows:

where:

$$
Z K I=\frac{(0.5 \times(\text { Class } 1+2 \times \text { Class } 2+3 \times \text { Class } 3)-0.5)}{\frac{\mathrm{S}}{\mathrm{Smax}}}
$$

Class $\mathrm{i}$ is a ratio of sum of dry weight of the species belonging to class $\mathrm{i}$ to total invertebrate biomass at station; $\mathrm{S}$ is number of species/taxa at station; Smax is a waterbody-specific value of maximum species number at station.

The values of ZKI index vary between 0 and 1 i.e. 1 representing the healthy communities and 0 representing the most deteriorated communities.

There are certain criteria that need to be fulfilled:

(1) The index can be used for soft bottom communities including mixed sand sediments.

(2) Sampling device is either a van Veen or Ekman type benthic grab.

(3) Depth should be $\geq 5 \mathrm{~m}$ and $\leq 30 \mathrm{~m}$.

\subsubsection{Number of functional traits (NFT)}

One of the most promising of the recently proposed approaches to measure community functional diversity is Biological Traits Analysis. Biological traits analysis uses a series of life history, morphological and behavioural characteristics of species present in assemblages to indicate aspects of their ecological functioning. The roles performed by benthic species are important for regulating ecosystem processes and these roles are determined by the biological traits species exhibit. The approach aims to provide a description of multiple aspects of functioning based on features of the biological ecosystem component. It does this by utilising specific species traits as indicators of functioning and examining the occurrence of these traits over assemblages. Community structure is governed by habitat variability and the biological traits exhibited by organisms will provide information about how they behave and respond to stress, thereby indicating the state of the environment.

Biological Traits Analysis is based on habitat template theory, which states that species' characteristics evolve in response to habitat constrain. Community structure is governed by habitat variability and the biological traits exhibited by organisms will provide information about how they behave and respond to stress, thereby indicating the state of the environment. BTA uses a number of analyses to describe patterns of biological trait composition over entire assemblages (i.e. the types of trait present in assemblages and the relative frequency with which they occur).

The index counts the number of functions (biological traits) in the system. Higher number reflects elevated functional diversity and, thus, such communities are able to provide more ecosystem services compared to those communities that have lower number of functions. In the current index the observed benthic invertebrate species were classified according to their mobility (mobile and non- 
migratory) and feeding type (suspension feeders, herbivores, deposit-feeders, and carnivores) based on literature [23] and field observations. Benthic macrophyte species were classified according to their growth form (coarsely branched, filamentous, sheet, thick leathery).

\subsubsection{Community heterogeneity $(\mathrm{CH})$}

The index analyses heterogeneity of communities at the landscape scale. In order to do so we quantify the relative importance of scale-specific variability of macrophyte and benthic invertebrate communities. Using multivariate data analyses dissimilarities between pairs of samples are calculated using a zeroadjusted Bray-Curtis coefficient (e.g. using PRIMER software package). The coefficient is known to outperform most other similarity measures and enables samples containing no organisms at all to be included. Then the geographical distances between the studied sites are calculated and the distances are related to the dissimilarity matrices of biota. The ratio between the distance-based mean dissimilarities and its standard deviation is used as a proxy of the community heterogeneity at landscape scale. As such the index estimates the complexity of the spatial patterns of benthic communities with higher values of the statistic indicating more distinct and less variable (i.e. potentially less disturbed) communities at the studied spatial scale.

The equation of a zero-adjusted Bray-Curtis coefficient is:

$$
d B C C(i, j)=\frac{\sum_{k=0}^{n-1}|y i, k-y j . k|}{\left[2+\sum_{k=0}^{n-1}(y i, k+y j, k)\right]}
$$

In the equation $\mathrm{dBCC}$ is the Bray-Curtis dissimilarity between the objects $\mathrm{i}$ and $\mathrm{j}$; $\mathrm{k}$ is the index of a variable and $\mathrm{n}$ is the total number of variables $\mathrm{y}$. A zeroadjusted Bray-Curtis coefficient includes a virtual dummy variable being 1 for all objects. Consequently, the result is not undefined, when the variables among two objects are entirely 0 . In the numerator this variable subtracts to zero and in the denominator it sums to 2 .

The equation of the scale-specific community heterogeneity is:

$$
C H i=\frac{\operatorname{mean}(d B C C i)}{\operatorname{stdev}(d B C C i)}
$$

where mean $(\mathrm{dBCC} i)$ is the mean zero-adjusted Bray-Curtis dissimilarity coefficient and stdev(dBCCi) is a standard deviation of this mean at a predefined spatial scale i. Response variables can be manifold: number of species, abundances, biomasses of species, functionality of community etc but in this study benthic species biomasses were used.

\subsection{Supporting environmental variables}

The values of water temperature, salinity and water velocity were obtained from the results of hydrodynamical model calculations from the early April 2011 to the early August 2012. The calculations were based on the COHERENS model which is a primitive equation ocean circulation model. It was formulated with 
spherical coordinates on a $1^{\prime} \times 1^{\prime}$ minute horizontal grid and 30 vertical sigma layers. The model was forced with hourly meteorological fields of $2 \mathrm{~m}$ air temperature, wind speed, wind stress vector, cloud cover and relative humidity. The meteorological fields were obtained from an operational atmospheric model. The model was validated against water level, temperature, salinity and water velocity measurements from the study area [24].

Finnish Meteorological Institute provided ice cover and thickness over the study area for 2010-2012. Ice cover and thickness were produced on daily basis at a nominal resolution of $500 \mathrm{~m}$ and were based on the most recent available ice chart and synthetic aperture radar (SAR) image. The ice regions in the ice charts were updated according to a SAR segmentation and new ice parameter values were assigned to each SAR segment based on the SAR backscattering and the ice thickness range at that location.

Based on bathymetry charts (available at the Estonian Marine Institute, University of Tartu) the inclination of coastal slopes was calculated at $50 \mathrm{~m}$ pixel resolutions using the Spatial Analyst tool of ArcInfo software [25]. High values of coastal slopes indicate the occurrence of topographic depressions or humps at the measured spatial scale. Low values refer to flat bottoms.

The Simplified Wave Model method was used to calculate the wave exposure for mean wind conditions represented by the ten-year period between 1 January 1997 and 31 December 2006 [26]. A nested-grids technique was used to take into account long-distance effects on the local wave exposure regime. The resulting grids had a resolution of $25 \mathrm{~m}$. In the modelling the shoreline was divided into suitable calculation areas, fetch and wave exposure grids were calculated and subsequently the separate grids were integrated into a seamless description of wave exposure along the study area. This method results in a pattern where the fetch values are smoothed out to the sides, and around island and skerries in a similar way that refraction and diffraction make waves deflect around islands.

As a proxy of eutrophication we used the MODIS satellite derived water transparency $(\mathrm{kd})$ and water chlorophyll a values. The frequency of satellite observations was generally weekly over the whole ice-free period, however, several observations were discarded due to cloudiness. The spatial resolution of satellite data was $1 \mathrm{~km}$. False zeroes were removed from the data prior to the statistical analysis.

The ESRI Spatial Analyst tool was used to calculate the average, minimum, maximum and variance of all abiotic and biotic variables (those obtained from field sampling as well as from modelling) for local i.e. sampling scale, $2 \mathrm{~km}$, $5 \mathrm{~km}$ and $10 \mathrm{~km}$ spatial scales. These values were used to link environmental and biotic patterns at larger spatial scales.

\subsection{Statistical analyses}

Ecological understanding is a prerequisite when it comes to selecting model environmental variables. It is plausible that traditional statistical modelling itself may not be the most rewarding way to disentangle the environmental-species relationships as it starts by assuming an appropriate data model and model 
parameters are then estimated from the data. By contrast, machine learning avoids starting with a data model and rather uses an algorithm to learn the relationship between the response and its predictors [27]. The novel predictive modelling techniques called Boosted Regression Trees (BRT) combine the strength of machine learning and statistical modelling. The BRT iteratively develop a large ensemble of small regression trees constructed from random subsets of the data. Each successive tree predicts the residuals from the previous tree to gradually boost the predictive performance of the overall model. Although BRT models are complex, they can be summarized in ways that give powerful ecological insight. BRT has no need for prior data transformation or elimination of outliers and can fit complex nonlinear relationships. What is most important in the ecological perspective it automatically handles interaction effects between predictors [28].

In this study we established relationships between environmental data and biotic indices using the BRT modelling. For BRT modelling the independent variables were: sampling depth, water temperature, salinity, velocity, ice cover, exposure to waves, coastal slope, chlorophyll a and $\mathrm{kd}$. They were regressed to predict the studied indices (ZKI, NFD, CH). For each indices, multiple models were run varying both the model learning rate (between 0.01 and 0.0001 ) and the number of trees (between 1000 and 10,000). Then the optimum model was selected based on model performance. Typically, optimal learning rates, number of trees and interaction depth were $0.01,3000$ and 5, respectively.

\section{Results}

The studied indices (ZKI, NFT, CH) responded to the changes in physical water properties (water temperature, salinity, and velocity), coastal topography (depth and coastal slope), ice scouring (ice cover and duration) and eutrophication (water transparency, phytoplankton biomass) with the BRT models describing between 40 and $99 \%$ of the variability of indices. Although diversity indices reacted differentially to the studied environmental variables, the links between environmental variables and indices were always the strongest at $5 \mathrm{~km}$ spatial scale. In general ice conditions, coastal topography and eutrophication had the strongest and physical water properties had the weakest effect to the studied indices. Among the studied indices, ZKI and NFT performed better compared to CH (Table 1, Fig. 1).

Although elevated eutrophication raised $\mathrm{ZKI}$ and decreased $\mathrm{CH}$ values at all spatial scales, the strength of relationship between eutrophication and the indices increased with spatial scales. At smaller spatial scales all studied indices primarily reflected changes in ice conditions and bathymetry. In contrast to ZKI and $\mathrm{CH}$, eutrophication did not have a clear effect on NFT.

\section{Discussion}

Our study clearly indicates that relationships between the environment and diversity indices are scale-dependent. At small spatial scales, in general, the 
Table 1: The separate contribution of the studied environmental variables in the BRT models calculated at $5 \mathrm{~km}$ scale. Model total denotes explained deviance of the full model, * denotes local spatial scale of an environmental variable, $* * 2 \mathrm{~km}, * * * 5 \mathrm{~km}$ and $* * * * 10 \mathrm{~km}$ spatial scales, respectively.

\begin{tabular}{|c|c|c|c|}
\hline & ZKI & NFT & $\mathrm{CH}$ \\
\hline Chlorophyll a & $16.580654 * * * *$ & $14.809846 * *$ & $4.073755 * * *$ \\
\hline Coastal slope & $11.392201 * * *$ & $14.537923 * *$ & $10.349796 * * *$ \\
\hline Depth & $12.238943 * * *$ & $15.508000^{*}$ & $0.721811 * * *$ \\
\hline Exposure & $11.838919 * * *$ & $6.853526^{*}$ & $1.124282 * * *$ \\
\hline Ice cover & $12.193292 *$ & $9.417511 * *$ & $0.672768 * * *$ \\
\hline Ice duration & $18.378936^{* * * *}$ & $10.641423 * * *$ & $0.291130 * * *$ \\
\hline Ice thickness & $11.224727^{*}$ & $50.438830 * * *$ & $0.790414 * * *$ \\
\hline Salinity & $6.189562 *$ & $22.760270 * * *$ & $29.542174 * * *$ \\
\hline Water temperature & $15.399426 * * *$ & $6.923844 *$ & $3.224029 * * *$ \\
\hline Water transparency $(\mathrm{kd})$ & $9.923706 * * *$ & $17.521697^{*}$ & $5.869383 * * *$ \\
\hline Velocity & $10.698818^{*}$ & $11.900348^{* *}$ & $2.722367 * * *$ \\
\hline Model total & $0.9236652 * * *$ & $0.995716^{* * *}$ & $0.205100 * * *$ \\
\hline
\end{tabular}

Macrozoobenthos community index (ZKI)
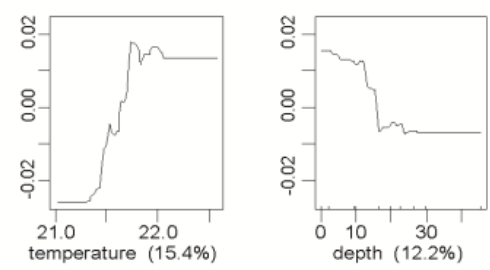

Number of functional traits (NFT)
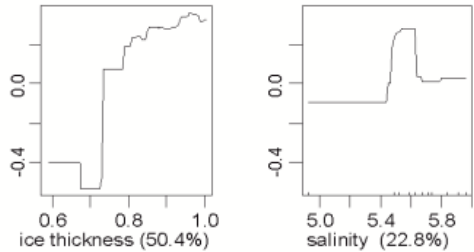

Community heterogeneity $(\mathrm{CH})$
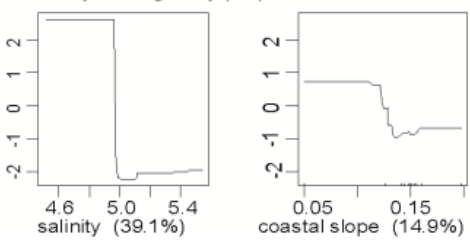
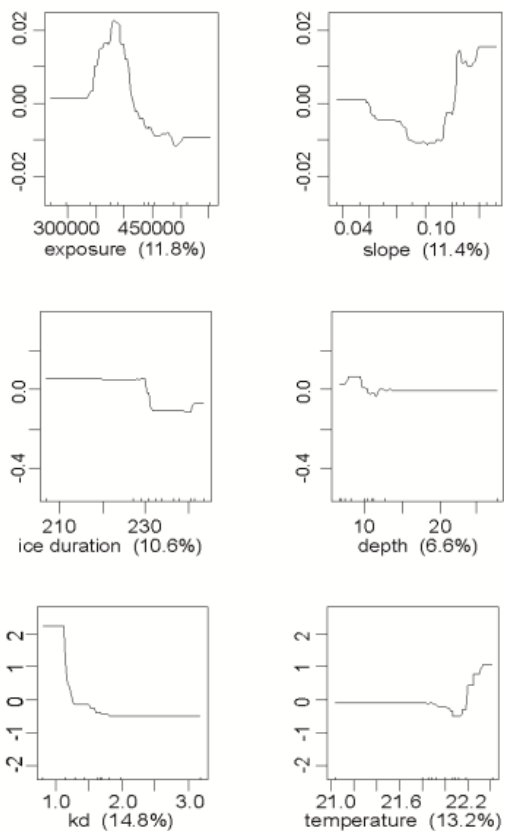

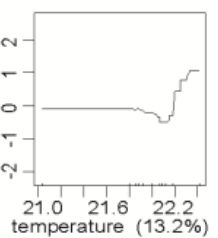

Figure 1: Functional relationship between environment and the indices at $5 \mathrm{~km}$ spatial scale. Only the best four variables are shown. 
indices reflect changes to local ice conditions and/or coastal topography. At larger spatial scales, however, the indices follow well the variability in coastal eutrophication. Thus, these are the scales where eutrophication processes are likely to have the largest effects on coastal environment and at which the impacts of eutrophication on coastal biota should be assessed.

These results are a direct consequence of strong natural disturbances operating at local spatial scales of the Baltic Sea ecosystems [e.g. 10, 29]. Such stochastic disturbances generate a patchy and mosaic seascape pattern - the scatter, in statistical terms, that hinders the detection of the eutrophication signal at local spatial scales.

Our study also showed that elevated eutrophication raised ZKI but decreased $\mathrm{CH}$ values. This indicates the differential response of eutrophication to local and seascape-scale benthic diversity. Locally, the biomass of macrophyte species is a function of nutrient availability and that of benthic invertebrates by macrophytes $[18,30-32]$. Thus, an increasing eutrophication of the Baltic Sea ecosystem relaxes competitive interactions for food and increases a chance of any benthic species to be observed. Consequently, local species diversity increases with eutrophication [20]. Too high a nutrient loading, however, is known to cause hypoxia and irreversible changes in communities [33]. Nevertheless, such conditions are not met in the study area.

In contrast, there was an inverse relationship between eutrophication and $\mathrm{CH}$. If $\mathrm{ZKI}$ is genuinely a local diversity index then $\mathrm{CH}$ reflects patchiness in the seascape. It is known that an increased eutrophication tends to homogenize the seascape patchiness by increasing the cover of filamentous algae irrespective of physical water properties and local topography [e.g. 30]. Besides, eutrophication deteriorates underwater light conditions and therefore further reduces overall biological diversity as in such a low-light environment only a few algal and associated invertebrate species can be found [34]. Consequently, an inverse relationship between eutrophication and $\mathrm{CH}$ is expected.

To conclude, despite of a presence of multitude natural disturbances and an opportunistic character of the majority of benthic species inhabiting the Baltic Sea, the studied diversity indices responded surprisingly well to changes in natural abiotic environment as well as to eutrophication. The eutrophication induced effects were the strongest at seascape scales. These are the scales at which the impacts of eutrophication on coastal biota should be assessed either in the frame of EU Habitat Directive or Marine Strategy Framework Directive with list of indicator classes and favourable reference values (GES targets) yet to be set.

\section{Acknowledgements}

This work was funded by target financed project SF0180013s08 of the Estonian Ministry of Education and Research and by the Estonian Science Foundation grants 7813 and 8254 . The study has been partly supported by the projects "EstKliima" No 3.2.0802.11-0043 and "The status of marine biodiversity and its potential futures in the Estonian coastal sea" No 3.2.0802.11-0029 of 
Environmental protection and -technology programme of European Regional Fund and the LIFE+ project No. LIFE09 NAT/LV/000238 MARMONI "Innovative approaches for marine biodiversity monitoring and assessment of conservation status of nature values in the Baltic Sea".

\section{References}

[1] Loreau, M., Naeem, S., Inchausti, P., Bengtsson, J., Grime, J.P., Hector, A., Hooper, D.U., Huston, M.A., Raffaelli, D., Schmid, B., Tilman, D. and Wardle, D.A., Biodiversity and Ecosystem Functioning: Current Knowledge and Future Challenges. Science, 294, pp. 804-808, 2001.

[2] Hector, A. and Bagchi, R., Biodiversity and ecosystem multifunctionality. Nature, 448, pp.188-191, 2007.

[3] Schiewer, U., The Baltic Sea. Ecology of Baltic Coastal waters, ed. U. Schiewer, Springer-Verlag: Berlin, pp. 1-10, 2008.

[4] Kautsky, H. and Van der Maarel, E., Multivariate approaches to the variation in benthic communities and environmental vectors in the Baltic Sea. Mar. Ecol. Progr. Ser., 60, pp. 169-184. 1990.

[5] Jansson, B.O., The Baltic Sea. Large Marine Ecosystems of the World, ed. G. Hempel and K. Sherma, Elsevier Science: Amsterdam, pp. 145-170, 2003.

[6] Kiirikki, M., Mechanisms affecting macroalgal zonation in the northern Baltic Sea. Eur. J. Phycol., 31, pp. 225-232, 1996.

[7] Bäck, S. and Ruuskanen, A., Distribution and maximum growth depth of Fucus vesiculosus along the Gulf of Finland. Mar. Biol. 136, pp. 303-307, 2000.

[8] Eriksson, B.K. and Johansson, G., Sedimentation reduces recruitment success of Fucus vesiculosus (Phaeophyceae) in the Baltic Sea. Eur. J. Phycol., 38, pp. 217-222, 2003.

[9] Wærn, M., Rocky-shore algae in the Öregrund archipelago. Acta Phytogeogr. Suec., 30, pp. 1-298, 1952.

[10] Herkül, K., Kotta, J., Kotta, I. and Orav-Kotta, H., Effects of physical disturbance, isolation and key macrozoobenthic species on community development, recolonisation and sedimentation processes. Oceanologia, 48S, pp. 267-282, 2006.

[11] Jansson, B.O. and Dahlberg, K., The environmental status of the Baltic Sea in the1940s, today and in the future. $A M B I O, 28$, pp. 312-319, 1999.

[12] Rönnberg, C. and Bonsdorff, E., Baltic Sea eutrophication: area-specific ecological consequences. Hydrobiologia, 514, pp. 227-241, 2004.

[13] Conley, D.J., Carstensen, J., Aigars, J., Axe, P., Bonsdorff, E., Eremina, T., Haahti, B.-M., Humborg, C., Jonsson, P., Kotta, J., Lännegren, C., Larsson, U., Maximov, A., Rodriguez Medina, M., Lysiak-Pastuszak, E., Remeikaité-Nikiené, N., Walve, J., Wilhelms, S. and Zillén, L., Hypoxia is increasing in the coastal zone of the Baltic Sea. Environ. Sci. Technol., 45, pp. 6777-6783, 2011. 
[14] Kotta, J., Kotta, I., Simm, M. and Põllupüü, M., Separate and interactive effects of eutrophication and climate variables on the ecosystem elements of the Gulf of Riga. Estuarine, Coastal and Shelf Science, 84, pp. 509-518, 2009.

[15] Ojaveer, H., Kotta, J., Põllumäe, A., Põllupüü, M., Jaanus, A. and Vetemaa, M., Alien species in a brackish water temperate ecosystem: Annual-scale dynamics in response to environmental variability. Environ. Res., 111, pp. 933-942, 2011.

[16] Paalme, T., Kotta, J., Kersen, P., Martin, G., Kukk, H. and Torn, K., Interannual variations in biomass of loose lying algae Furcellaria-Coccotylus community: The relative importance of local versus regional environmental factors in the West Estonian Archipelago. Aquat. Bot., 95, pp. 146-152, 2011.

[17] Bulleri, F., Benedetti-Cecchi, L., Cusson, M., Maggi, E., Arenas, F., Aspden, R., Bertocci, I., Crowe, T.P., Davoult, D., Eriksson, B.K., Fraschetti, S., Golléty, C., Griffin, J., Jenkins, S.R., Kotta, J., Kraufvelin, P., Molis, M., Sousa Pinto, I., Terlizzi, A., Valdivia, N. and Paterson, D.M., Temporal stability of European rocky shore assemblages: variation across a latitudinal gradient and the role of habitat-formers. Oikos, 121, pp. 18011809, 2012.

[18] Lauringson V. and Kotta J., Influence of the thin drift algal mats on the distribution of macrozoobenthos in Kõiguste Bay, NE Baltic Sea, Hydrobiologia, 554(1), pp. 97-105, 2006.

[19] Hewitt, J.E. and Thrush, S.F., Reconciling the influence of global climate phenomena on macrofaunal temporal dynamics at a variety of spatial scales. Glob. Change Biol., 15, pp. 1911-1929, 2009.

[20] Kotta, J., Paalme, T., Püss, T., Herkül, K. and Kotta, I., Contribution of scale-dependent environmental variability on the biomass patterns of drift algae and associated invertebrates in the Gulf of Riga, northern Baltic Sea. J. Mar. Syst., 74(1), pp. S116-S123, 2008.

[21] HELCOM., Guidelines for Monitoring of Phytobenthic Plant and Animal Communities in the Baltic Sea. Annex for HELCOM COMBINE Programme. Compiled by S. Bäck. 1999.

[22] Kotta, J., Lauringson, V., Kaasik, A. and Kotta, I., Defining the coastal water quality in Estonia based on benthic invertebrate communities. Est. J. Ecol., 61, pp. 86-105, 2012.

[23] Bonsdorff, E. and Pearson, T.H., Variation in the sublittoral macrozoobenthos of the Baltic Sea along environmental gradients; a functional-group approach. Aust. J. Ecol., 24, pp. 312-326, 1999.

[24] Bendtsen, J., Gustafsson, K.E., Söderkvist, J. and Hansen, J.L.S., Ventilation of bottom water in the North Sea-Baltic Sea transition zone. $J$. Mar. Syst., 75, pp. 138-149, 2009.

[25] ESRI, ArcGIS Desktop: Release 10. Redlands, CA: Environmental Systems Research Institute. 2011. 
[26] Isæus, M., Factors structuring Fucus communities at open and complex coastlines in the Baltic Sea. PhD Thesis, Department of Botany, Stockholm University, Sweden, 2004.

[27] Hastie, T., Tibshirani. R. and Friedman, J.H., The Elements of Statistical Learning: Data Mining, Inference and Prediction. Springer-Verlag: New York, 2009.

[28] Elith, J., Leathwick, J.R. and Hastie, T., A working guide to boosted regression trees. J. Anim. Ecol. 77, pp. 802-813, 2008.

[29] Kotta, J., Lauringson, V., Martin, G., Simm, M., Kotta, I., Herkül, K. and Ojaveer, H., Gulf of Riga and Pärnu Bay. Ecology of Baltic Coastal waters, ed. U. Schiewer, Springer-Verlag: Berlin, 197, pp. 217-243, 2008.

[30] Kotta, J., Paalme, T., Martin, G. and Mäkinen, A., Major changes in macroalgae community composition affect the food and habitat preference of Idotea baltica. Internat. Rev. Hydrobiol., 85, pp. 693-701, 2000.

[31] Paalme, T., Kukk, H., Kotta, J. and Orav, H., 'In vitro' and 'in situ' decomposition of nuisance macroalgae Cladophora glomerata and Pilayella littoralis, Hydrobiologia, 475/476, pp. 469-476, 2002.

[32] Kotta, J. and Ólafsson, E., Competition for food between the introduced exotic polychaete Marenzelleria viridis and the resident native amphipod Monoporeia affinis in the Baltic Sea. J. Sea Res., 50(1), pp. 27-35, 2003.

[33] Karlson, K., Rosenberg R. and Bonsdorff E., Temporal and spatial largescale effects of eutrophication and oxygen deficiency on benthic fauna in Scandinavian and Baltic waters - a review, Oceanogr. Mar. Biol. Ann. Rev., 40, pp. 427-489, 2002.

[34] Kotta, J., Simm, M., Kotta, I., Kanošina, I., Kallaste, K. and Raid, T., Factors controlling long-term changes of the eutrophicated ecosystem of Pärnu Bay, Gulf of Riga. Hydrobiologia, 514, pp. 259-268, 2004. 